\section{Max Oertel}

Max Josef Oertel, one of the most eminent and versatile German physicians of the second half of the nineteenth century, was born at Dillingen in Bavaria on March 20, 1835. He first studied under Prof. von Pettenkofer at Munich, where he made a considerable number of analyses of the air in various public institutions and private houses which he published in a work entitled "Experiments on the Accumulation of Carbonic Acid in Inhabited Localities". Afterwards he devoted himself to the study of diseases of the throat, including diphtheria, on which he published some of the most important articles on the causation of the disease prior to the discovery of the Klebs-Loeffler bacillus. His other works on diseases of the throat were concerned with tumours of the larynx, instruction in laryngology, and treatment of respiratory affections. Oertel was the first physician in South Germany to lecture on laryngology, and was appointed extraordinary professor of laryngology at Munich in 1876, which office he held until his death on July 19, 1897. He was also well known as a general physician and particularly for his treatment of diseases of the heart, in which he paid special attention to diet and exercise.

\section{Award of the Duddell Medal to Dr. W. E. Williams}

THE council of the Physical Society has awarded the twelfth Duddell Medal to Dr. W. Ewart Williams, lecturer in physies at King's College, London, who is distinguished for his work in optical design, chiefly in the region of interferometry. The Medal is given to "persons who have contributed to the advancement of knowledge by the invention or design of scientific instruments, or by the discovery of materials used in their construction". The principal invention of Dr. Williams is that of the reflection echelon spectroscope. The basic idea of such an instrument was described by the late Prof. Michelson nearly forty years ago, but its practical construction seemed impossible until the discovery by Williams that two optically plane surfaces of quartz or fused silica could be placed in permanent optical contact without exerting the mechanical force needed with glass surfaces. He saw that a number of fused silica plates of exactly equal thickness could be built up in the necessary echelon formation without introducing any distortion that would ruin the optieal performance of the instrument. The reflection echelon is the only form of spectroscope of sufficient resolving power which can be used in the ultra-violet part of the spectrum, where, in a number of cases, lie the lines of greatest interest from the point of view of 'fine structure', a detailed study of which gives us information about the structure of the nucleus in its normal state.

By adding two small mirrors to the echelon and mounting it in an evacuated chamber, Dr. Williams has adapted the instrument, originally meant for finestructure work only, for the accurate measurement of the wave-lengths of the lines. In consequence of the far greater resolving power now available, the wave-lengths of the lines can be measured with a corresponding greater degree of accuracy, and the method of calculation is far simpler and more rapid than with the Fabry-Perot interferometer. He has also devised a method of standardising the metre in terms of wave-lengths by means of the reflection echelon. This permits the number of wave-lengths contained in a gauge of approximately a metre length to be determined in two operations, as distinct from the numerous stages involved in the present methods. The principle of the reflection grating has been also applied by him to directional aerial systems for short-wave wireless transmitters, which are being used in America, and he has improved a number of optical instruments, amongst which are the Rayleigh refractometer and (in conjunction with Mr. F. Twyman) the Fabry-Perot interferometer.

\section{National Inland Water Survey}

IN the discussion which followed the reading of Dr. Brysson Cunningham's Paper on National Inland Water Survey, a summary of which appears on p. 443 of this issue, Vice-Admiral Sir Percy Douglas, the chairman of the British Association Research Committee on the subject, described the work of the Committee subsequent to the date of the reception of the deputation by the Minister of Health, and expressed the gratification which he felt at the unanimous agreement of the members of the Com. mittee on a draft outline of the scope of the survey which had been drawn up and forwarded to the British Association, and which he hoped would be recorded in the Geographical Journal, for which purpose he read the several items. Dr. H. R. Mill spoke of the association of the Royal Geographical Society with water survey, and alluded in particular to the observations made on the Exe and the Medway with which he had been connected. Sir Henry Lyons, chairman of the new Survey Committee, welcomed the interest taken in the matter, and said that as his Committee had only just met quite recently for the first time, it would be premature at present for him to express any views on the course of action which he and his colleagues might decide to take. Capt. W. N. McClean described the more important features of River Flow Records, and showed how he had built up an organisation which he considered might be of great assistance in the work of river and stream gauging. Mr. G. J. Griffiths, chief enginoer of the Thames Conservancy Board, emphasised the value of river flow records and the advantage which had accrued from having prolonged observations at Teddington and elsewhere; he considers a national survey to be long overdue. Dr. Bernard Smith dealt with the importance of observations relating to underground water and the necessity of prosecuting researches thereon in all practicable directions.

\section{Preservation of Sites of Scientific Interest}

THE British Association has recently been receiving from the Ministry of Health information of all schemes in progress under the Town and Country Planning 